\title{
Nachweis von Atemwegsviren - Wie, warum, wann und wo?
}

\section{Detection of Respiratory Viruses - How, When, Where and Why?}

Autoren

Institute

\section{G. Rohde' , C. Drosten², I. Borg'1, B. Hauptmeier', F. Ringshausen' ${ }^{1}$, G. Schultze-Werninghaus ${ }^{1}$, K. Überla ${ }^{3}$}

Medizinische Klinik III - Pneumologie, Allergologie und Schlaf- und Beatmungsmedizin, Berufsgenossenschaftliches Universitätsklinikum Bergmannsheil GmbH, Bochum 2 Institut für Virologie, Universitätsklinikum Bonn

Abteilung für Molekulare und Medizinische Virologie, Ruhr-Universität Bochum

\section{Bibliografie}

DOI $10.1055 / \mathrm{s}-2008-1038292$

Online-Publikation: 9. 1.2009

Pneumologie 2009; 63: 14-22

(c) Georg Thieme Verlag KG

Stuttgart · New York

ISSN 0934-8387

Korrespondenzadresse

Jun.-Prof. PD Dr. med.

Gernot Rohde

Medizinische Klinik III,

Pneumologie, Allergologie,

Schlaf- und Beatmungsmedizin, Berufsgenossenschaftliches

Universitätsklinikum

Bergmannsheil $\mathrm{GmbH}$

Bürkle-de-la-Camp-Platz 1

44789 Bochum

Gernot.Rohde@ruhr-uni-

bochum.de

Serienherausgeber

C. Lange, Borstel

G. Rohde. Bochum

B. Schaaf, Dortmund

\section{Zusammenfassung}

Atemwegsviren sind für die überwiegende Mehrzahl aller so genannten Erkältungskrankheiten und grippalen Infekte in der kalten Jahreszeit, akuter respiratorischen Erkrankungen im Kindesalter sowie akuter Exazerbationen von Asthma bronchiale und chronisch obstruktiver Lungenerkrankungen (COPD) verantwortlich und spielen eine nicht zu vernachlässigende Rolle bei der ambulant erworbenen Pneumonie. Leider ist der Nachweis von Atemwegsviren bis heute schwierig. In dieser Übersicht werden daher die wesentlichen Untersuchungsverfahren vorgestellt und der aktuelle Stand des Wissens über die klinische Bedeutung von Atemwegsviren bei den unterschiedlichen Erkrankungen präsentiert.

\section{Einleitung \\ $\nabla$}

Atemwegsviren sind für eine große Anzahl akuter respiratorischer Erkrankungen verantwortlich und führen oft bei Patienten mit chronischen Atemwegserkrankungen zu Exazerbationen. Die wichtigsten Krankheitsbilder umfassen die so genannten Erkältungskrankheiten und grippalen Infekte in der kalten Jahreszeit, die Virusgrippe (Influenza), die Respiratory-Syncytial-Virus (RSV)-Bronchiolitis bei Kindern, die Viruspneumonie (meist ambulant erworben) sowie die akuten Exazerbationen des Asthma bronchiale und der chronisch obstruktiven Lungenerkrankung (COPD). Zu den pathogenetisch bedeutsamen Viren gehören Rhino-, Influenza-, RS-Corona-, Parainfluenza- und Adenoviren ( $\bullet$ Tab. 1 ). In den letzten Jahren wurden zusätzlich eine Reihe neuer Atemwegsviren wie das humane Metapneumonvirus, neue Varianten der Coronaviren $(\mathrm{CoV})$ inklusive des Severe Acute Respiratory Syndrom (SARS)-CoV oder das humane Bocavirus entdeckt. Bei einigen dieser Viren ist die pathoge-

\section{Abstract \\ $\nabla$}

Respiratory viruses trigger the majority of common colds, acute respiratory illnesses in children during the cold season as well as acute exacerbations of asthma and chronic obstructive pulmonary disease. They also play a role in community acquired pneumonia. Unfortunately their detection is still difficult. The aim of this review is therefore to introduce the methods of detection and to present the current knowledge of the clinical role of respiratory viruses in different diseases.

netische Bedeutung noch nicht abschließend geklärt. Ein besonderes Risiko stellen Infektionen durch Atemwegs- und andere Viren für Patienten mit Immunsuppression dar.

Eine besondere Schwierigkeit stellt der Nachweis der Atemwegsviren dar. Um dieses Problem genau zu erfassen, ist die Kenntnis der unterschiedlichen Nachweisverfahren unentbehrlich. Im Folgenden werden daher zunächst die unterschiedlichen Verfahren kurz dargestellt.

\section{Nachweisverfahren \\ $\nabla$}

Unterscheiden kann man den indirekten, auf der Antikörperserologie beruhenden, von dem direkten Virusnachweis ( $\bullet$ Tab.2). Das letztere Verfahren beruht auf dem Nachweis der Erreger selbst, einzelner viraler Proteine oder aber der viralen Erbinformation. Mit Ausnahme von latenten oder persistierenden Infektionen ist der direkte Nachweis nur während der akuten Erkrankungsphase, häufig sogar nur vor dem Auftreten 
Tab.1 Atemwegsviren

\begin{tabular}{|c|c|c|c|c|c|c|}
\hline Virus & Familie & Größe & Genom & $\begin{array}{l}\text { Genom- } \\
\text { größe }\end{array}$ & $\begin{array}{l}\text { Sero- } \\
\text { typen }\end{array}$ & Rezeptor \\
\hline $\begin{array}{l}\text { Respiratory } \\
\text { Syncytial Virus }\end{array}$ & Paramyxoviridae & $150-250 \mathrm{~nm}$ & $\begin{array}{l}\text { Einzelstrang-RNA in } \\
\text { Negativstrangorientierung }\end{array}$ & $15,2 \mathrm{~kb}$ & $A, B$ & $\begin{array}{l}\text { Heparin-ähnliche } \\
\text { Glykosaminoglykan- } \\
\text { Reste }\end{array}$ \\
\hline $\begin{array}{l}\text { humanes } \\
\text { Metapneumovirus }\end{array}$ & Paramyxoviridae & $150-250 \mathrm{~nm}$ & $\begin{array}{l}\text { Einzelstrang-RNA in } \\
\text { Negativstrangorintierung }\end{array}$ & $15,2 \mathrm{~kb}$ & 1 & $\begin{array}{l}\text { nicht eindeutig } \\
\text { identifiziert }\end{array}$ \\
\hline Parainfluenzaviren & Paramyxoviridae & $150-250 \mathrm{~nm}$ & $\begin{array}{l}\text { Einzelstrang-RNA in } \\
\text { Negativstrangorientierung }\end{array}$ & $15,2 \mathrm{~kb}$ & $1-4$ & $\begin{array}{l}\text { nicht eindeutig } \\
\text { identifiziert }\end{array}$ \\
\hline Influenza A-C & $\begin{array}{l}\text { Orthomyxoviri- } \\
\text { dae }\end{array}$ & $120 \mathrm{~nm}$ & $\begin{array}{l}\text { segmentierte RNA in } \\
\text { Negativstrangorientierung }\end{array}$ & $12,9-24,6 \mathrm{~kb}$ & $A, B, C$ & $\begin{array}{l}\text { N-Actylneuramin- } \\
\text { säure }\end{array}$ \\
\hline Rhinoviren & Picornaviridae & $30 \mathrm{~nm}$ & $\begin{array}{l}\text { Einzelstrang-RNA in } \\
\text { Plusstrangorientierung }\end{array}$ & $7,2 \mathrm{~kb}$ & $>100$ & $\begin{array}{l}\text { ICAM-1 } \\
\text { (major group) } \\
\text { LDL-Rezeptor } \\
\text { (minor group) }\end{array}$ \\
\hline $\begin{array}{l}\text { Coronaviren } \\
\text { (inkl. SARS) }\end{array}$ & Coronaviridae & $80-160 \mathrm{~nm}$ & $\begin{array}{l}\text { Einzelstrang-RNA in } \\
\text { Plusstrangorientierung }\end{array}$ & $20-30 \mathrm{~kb}$ & $\begin{array}{l}\text { HCoV-2- } \\
29 \mathrm{E}, \\
\text {-OC43, } \\
\text {-NL63, } \\
\text {-HKU1, } \\
\text { SARS- } \\
\text { CoV }\end{array}$ & $\begin{array}{l}\text { Aminopeptidase N } \\
\text { (229E-Gruppe), } \\
\text { 9-O-acetylierte } \\
\text { Neuraminsäurereste } \\
\text { (OC43 Gruppe), } \\
\text { HLA-1 (OC43), ACE2 } \\
\text { (SARS, NL63) }\end{array}$ \\
\hline Adenovirus & Adenoviridae & $80-110 \mathrm{~nm}$ & $\begin{array}{l}\text { doppelsträngige lineare } \\
\text { DNA }\end{array}$ & $36-38 k b$ & $>50$ & $\begin{array}{l}\text { CAR-Rezeptor (Cox- } \\
\text { sackie- and Adeno- } \\
\text { virusrezeptor) }\end{array}$ \\
\hline
\end{tabular}

Tab.2 Verfahren zum Virusnachweis

\begin{tabular}{|c|c|c|c|c|}
\hline & Verfahren & Material & Ergebnis nach & Spektrum \\
\hline \multirow[t]{5}{*}{ Direkter Virusnachweis } & Viruskultur & $\begin{array}{l}\text { Blut, Serum, Rachenspülwasser, } \\
\text { Sputum, TS, BAL }\end{array}$ & 1-2 Wochen & unvollständig \\
\hline & Shell-Vial Assay & $\begin{array}{l}\text { Blut, Serum, Rachenspülwasser, } \\
\text { Sputum, TS, BAL }\end{array}$ & $1-2$ Tage & unvollständig \\
\hline & Direkte Immunfluoreszenz & Abstrich, Spülproben & $1-2$ Stunden & $\begin{array}{l}\text { Influenza, Adeno-, RSV, } \\
\text { hMPV }\end{array}$ \\
\hline & ELISA/Immunchromatographie & $\begin{array}{l}\text { Nasenabstrich/Nasopharyngel- } \\
\text { sekret }\end{array}$ & $15 \mathrm{~min}$. & Influenza, RSV \\
\hline & Nachweis viraler Nukleinsäuren & Nasenlavage, Sputum, TS, BAL & 4-8 Stunden & alle \\
\hline Indirekter Virusnachweis & Serologie & Serum & $\begin{array}{l}\text { Titeranstieg nach } \\
2 \text { Wochen }\end{array}$ & $\begin{array}{l}\text { Influenza, Parainfluenza, } \\
\text { Adeno-, Rhino-, Corona-, } \\
\text { RS-Viren }\end{array}$ \\
\hline
\end{tabular}

ELISA= Enzyme-linked immunosorbentassay, TS = Trachealsekret, BAL = Bronchoalveoläre Lavage, RSV= Respiratory Syncytial Virus, hMPV=humanes Metapneumovirus

der ersten Symptome möglich. Der indirekte Nachweis ermöglicht meist die Diagnose erst im Nachhinein, da wegen hoher Durchseuchungsprävalenzen in der Regel die Untersuchung von Titerbewegungen in konsekutiven Seren notwendig ist. Deshalb sind Methoden für den direkten Virusnachweis dem Antikörpernachweis überlegen und im Allgemeinen vorzuziehen.

\section{Direkte Nachweisverfahren \\ Viruskultur}

Adhärent wachsende Zelllinien werden mit möglichst steril gewonnenem Untersuchungsmaterial (Blut, Serum, Rachenspülwasser, Sputum, etc.) inkubiert. Die Zellen werden dann auf zytopathische Effekte (Einschlusskörperchen, Riesenzellbildung, etc.) und auf Virusantigene licht- und fluoreszenzmikroskopisch untersucht ( Abb.1). Meist ist mit dieser klassischen Methode eine lange Inkubationszeit verbunden (1-2 Wochen), so dass ein schnelleres Verfahren entwickelt wurde, das Shell-Vial-As- say (SVA). Hier werden die suszeptiblen Zellen mit dem potenziell virushaltigen Untersuchungsmaterial auf einer Mikrotiterplatte inkubiert und niedertourig zentrifugiert, was zu einer schnelleren Aufnahme der Viren in die Zellen führt (Aufzentrifugation von Virusaggregaten und Setzen eines Proliferationsreizes). Nach 1-2 Tagen kann man virale Proteine in den Zellen nachweisen [1]. Mittels genauer Analysen der Virusproteine oder -genome kann dann eine Bestimmung des Virustyps erfolgen. Das Verfahren ist insgesamt langsam, teuer, wenig sensitiv und liefert nur ein unvollständiges Nachweisspektrum (einige Viren wachsen nicht auf Zellkultur). Es kann für die routinemäßige Verwendung als obsolet angesehen werden, sollte jedoch wegen der Möglichkeit, neue Viren zu entdecken und Virusisolate zu erhalten, zumindest in infektionsmedizinisch spezialisierten Zentren mitgeführt werden. 

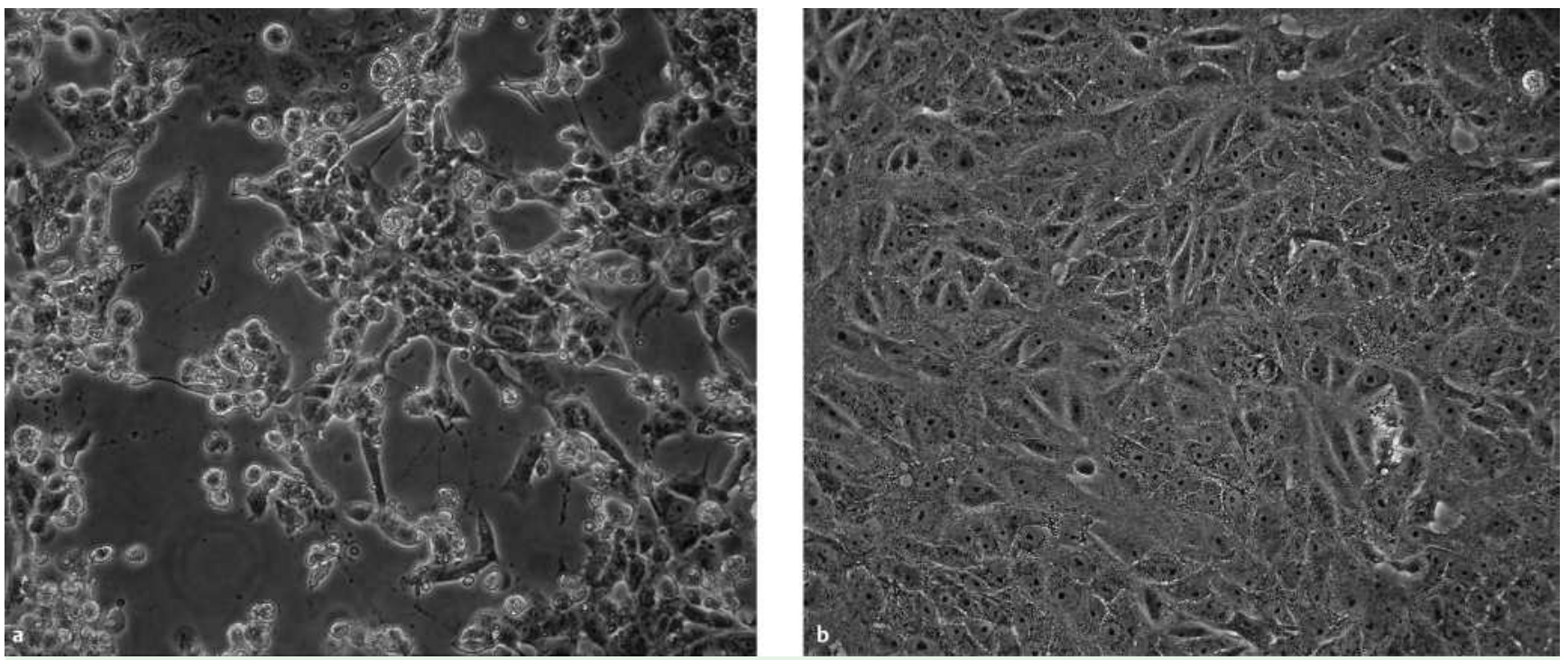

Abb. 1 Beispiel für Zellkultur, hier a Infektion von Verozellen mit SARS-CoV und deutlichem zytopathischem Effekt, b uninfizierte Vero-Zellen als Kontrolle.

\section{Nachweis viraler Antigene}

Direkte Immunfluoreszenz Es werden aus Abstrich- und Spülproben Zellen aus der respiratorischen Schleimhaut des Patienten aufgereinigt. Diese Zellen werden auf Mikroskop-Objektträgern fixiert, permeabilisiert und mit Anti-Virus-Antikörpern behandelt. Die Antikörper tragen einen Fluoreszenzmarker, der bei positivem Nachweis von Virusantigen in den Patientenzellen unter dem Mikroskop zu erkennen ist. Das Verfahren steht zur Verfügung für Influenza-, Adeno-, RSV- und humane Metapneumoviren. Es erlaubt einen relativ schnellen Nachweis (wenige Stunden) der genannten Viren zu geringen Kosten, ist aber leider auf die genannten Viren beschränkt.

Antigen-Capture ELISA und Immunchromatographie Beim Antigen-capture ELISA wird das Probenmaterial in Mikrotiterplatten gegeben, die mit einem Virus-spezifischen Antikörper beschichtet sind. Virale Antigene aus dem Probenmaterial, die an diese Antikörper gebunden haben, bleiben bei den darauf folgenden Waschschritten an die Platte gebunden und können durch einen zweiten Enzym-markierten Antikörper, der gegen dasselbe virale Antigen gerichtet ist, nachgewiesen werden. Die enzymatische Aktivität ist dabei proportional zur Menge des gebundenen viralen Antigens.

Ein ähnliches Geräte-unabhängiges Verfahren wird auch z. B. für die Influenza-Schnelltests verwendet und entspricht technisch einem Schwangerschaftstest. Hier werden Gold- oder Latexkügelchen $(20 \mu \mathrm{m}$ Durchmesser), die mit Virus-spezifischen Antikörpern beschichtet sind, mit dem Probenmaterial versetzt. Die Kügelchen binden über die Antikörper die möglicherweise im Probenmaterial enthaltenen Viren und wandern aufgrund von Kapillarkräften auf der Membran. Auf dieser Membran sind Antikörper aufgebracht, die die mit Virus beladenen Kügelchen aufhalten und dann als dunkle Bande sichtbar werden. Einziger Vorteil der Methode ist ihre Geschwindigkeit. Angesichts der therapeutischen Relevanz bleibt die Methode dem Nachweis von Influenzavirus vorbehalten. Dieses wird auch bei Erwachsenen mit vernünftiger Sensitivität, allerdings zu vergleichsweise hohen Kosten nachgewiesen. Von der Verwendung von Schnelltests für alle anderen respiratorischen Viren muss insbesondere in der Erwachsenenmedizin abgeraten werden, weil in den wenigen verfügbaren Studien Sensitivitäten unter $50 \%$ erzielt wurden.

\section{Nachweis viraler Nukleinsäuren}

Der Nachweis viraler Nukleinsäuren aus den unterschiedlichsten Probenmaterialien beruht auf der Polymerasekettenreaktion (polymerase chain reaction, PCR). Das Prinzip der PCR basiert auf der Amplifikation geringster Mengen von Virus-Nukleinsäure (Desoxyribonukleinsäure (DNA) oder Ribonukleinsäure (RNA)). Im Prinzip reicht ein einziges DNA-Molekül aus; bei RNA-Viren ist jedoch zunächst eine enzymatische Umschreibung in DNA nötig. Es werden sequenzspezifische einzelsträngige Oligonukleotide (Primer) verwendet, die sich an das Virusgenom anlagern. Mittels einer hitzefesten DNA-Polymerase wird ein komplementärer Nukleinsäurestrang synthetisiert. Es folgt eine Strangtrennung durch Erhitzen („Schmelzen“) und erneute Anlagerung von Primern. Dies wird bis zu fünfzigmal wiederholt, so dass eine Kettenreaktion mit exponenzieller Amplifikation zustande kommt (Verdopplung der DNA in jedem Zyklus - Exponenzialfunktion zur Basis 2). Die Amplifikate liegen dann in so großen Mengen vor, dass sie entweder auf einem Agarosegel sichtbar gemacht werden (qualitativer Test) oder einer Sondenhybridisierung unterzogen werden können (quantitativer Test, „real-time PCR“). Die Virusamplifikate sind nicht nur für die Virusfamilie, das Genus und die Unterfamilie spezifisch, sondern auch für die unterschiedlichen Serotypen. Daher kann man nach entsprechender Analyse (Sequenzierung) die Serotypen und mögliche Mutationen nachweisen. Die viralen Nukleinsäuren sind im eingefrorenen Zustand und korrekter Lagerung sehr beständig, so dass auch langfristig aufbewahrte Proben noch auf das Vorhandensein von Viren untersucht werden können. Der diagnostische Einsatz der PCR wurde insbesondere zum HIVund HCV-Virusnachweis perfektioniert.

Seit einigen Jahren besteht auch die Möglichkeit, Atemwegsviren mittels PCR nachzuweisen. Durch die hohe Sensitivität dieser Technik werden in neueren Studien deutlich höhere Nachweisraten von respiratorischen Viren nachgewiesen. Besonders interessant sind 2 technische Varianten der PCR: 1. Durch den Einsatz von Multiplex-Techniken ist der gleichzeitige Nachweis mehrerer Viren in einer Reaktion möglich [2]. Dies ist insbesondere bei den respiratorischen Infektionen von Bedeutung, da hier das infrage kommende Erregerspektrum besonders breit ist und in der Vergangenheit immer nur unvollständig erfasst wurde. 2. Durch die Möglichkeit, über real-time PCR quantitati- 

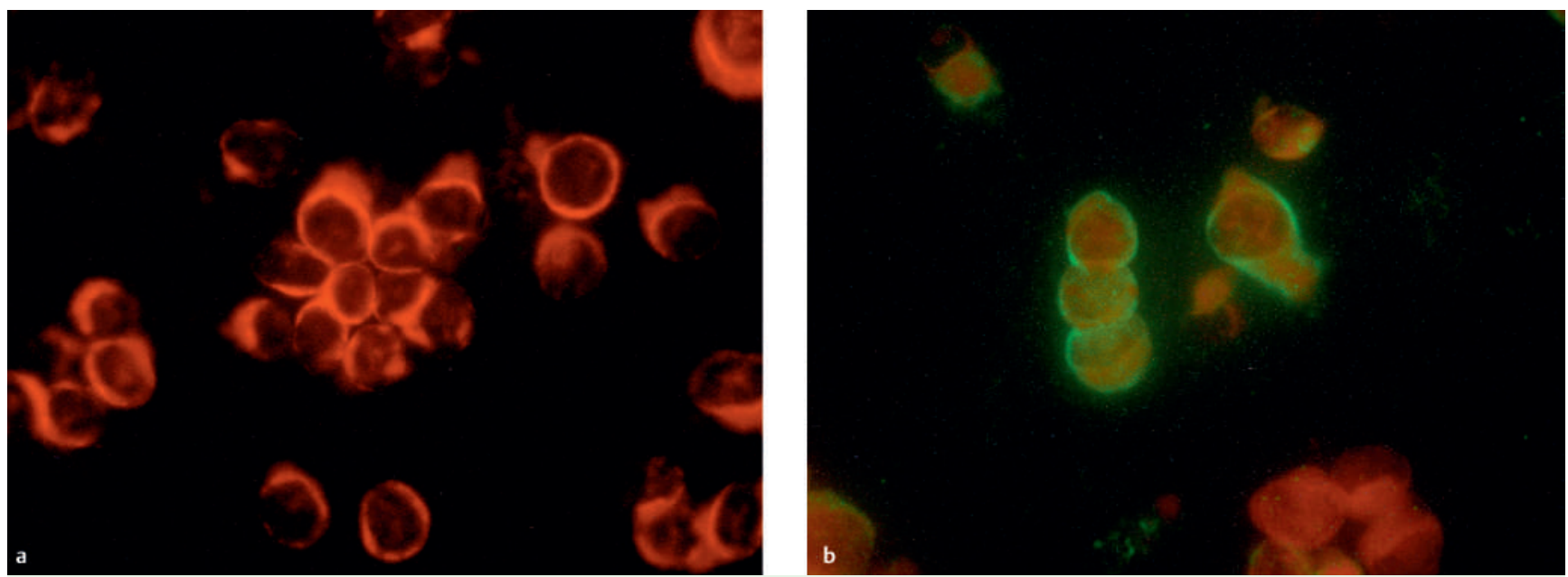

Abb.2 Antikörpernachweis durch Immunfluoreszenz. a mit Antikörper-freiem Serum sind alle Zellen gleichmäßig gefärbt (rot unspezifische Zellfärbung). b mit Antikörper-haltigem Serum färben sich diejenigen Zellen, die Virus-infiziert sind, grün. Die roten uninfizierten Zellen dienen der Kontrolle von unspezifischer Reaktivität.

ve Virusnachweise zu erzielen, wird in Zukunft eine Einschätzung der pathogenetischen Relevanz von Virusnachweisen verbessert (pathogene Bedeutung generell eher bei hohen Viruskonzentrationen; okkasionelle Befunde eher bei niedrigen Virustitern) [3]. Als Nebeneffekt wurde durch die Einführung der real-time PCR auch die Rate von falsch-positiven Nachweisen drastisch gesenkt [4].

Für den Einsatz in der Forschung modifizierte PCR-Techniken bieten auch eine hervorragende Möglichkeit, neue, bislang unbekannte Atemwegsviren zu entdecken [5]. Hier werden unterschiedliche, teilweise sehr komplexe Techniken eingesetzt, die u.a. zur Entdeckung des Coronavirus NL-63 und des humanen Bocavirus geführt haben [6].

Eine weitere, auch eher in der Forschung eingesetzte Möglichkeit des molekularen Virusnachweises besteht in der in situ-Hybridisierung. Hier wird virales Genom mithilfe spezifischer markierter DNA-Sonden in Gefrierschnitten von infizierten Zellen oder Geweben nachgewiesen. Die Auswertung erfolgt unter dem Mikroskop.

Der Nachweis von respiratorischen Viren per Multiplex-PCR hat das Verständnis von akuten respiratorischen Erkrankungen verändert und neue ätiologische Verknüpfungen zu Tage gefördert (s. unten). Die Technik muss heute als diagnostische Methode der Wahl gelten. Die nicht gegebene Kostendeckung verhindert jedoch weitgehend ihren Einsatz außerhalb spezialisierter Zentren. Hauptgrund für die hohen Kosten ist die Vielzahl von nachzuweisenden Viren - eine Aufsummierung je einer PCR-Leistungszahl pro Virus ist ökonomisch unrealistisch. Es ist dringend eine adäquate Darstellung in Leistungskatalogen erforderlich.

\section{Indirekte Nachweisverfahren}

Es werden die vom Patienten gebildeten Serum-Antikörper nachgewiesen ( Abb.2). Akut werden zunächst IgM-Antikörper gebildet, im Verlauf kommt es dann zu Bildung von IgG-Antikörpern [7]. Bei Zweitinfektion sind IgM-Antikörper kaum nachzuweisen. Aufgrund der hohen Durchseuchungsprävalenzen in der Normalbevölkerung ist es für die Diagnose einer akuten Infektion wesentlich, die Konzentrationen der Antikörper im Verlauf zu bestimmen. Ein mindestens 4 -facher Titeranstieg bei einem Serumpaar wird als diagnostisch bewertet. Es ist ein wesentlicher Nachteil dieser Methode, dass meist erst im Nach- hinein die Infektion gesichert werden kann. Zum Nachweis der Antikörper stehen folgende Verfahren zur Verfügung: WesternBlot, ELISA, indirekter Immunfluoreszenztest (IFT) und Komplementbindungsreaktion (KBR). Aufgrund des sinkenden Stellenwertes der Antikörperserologie bei den respiratorischen Viren werden methodische Details hier nicht behandelt. Abgesehen von epidemiologischen Anwendungen (z.B. Beurteilung von Influenza-Aktivität und Impfstoff-Spezifitäten) sollte der Antikörpernachweis als sekundäre Diagnostikmethode angesehen werden. Dies gilt in der Erwachsenenmedizin in noch stärkerem Maße als in der Pädiatrie.

\section{Relevanz der unterschiedlichen Methoden}

Auf Grund der hohen Sensitivität und der akzeptablen Untersuchungsdauer gewinnen die viralen Nukleinsäurenachweisverfahren bei viralen Atemwegsinfektionen zunehmend an Bedeutung. Ein direkter Vergleich der Nachweisraten mit Viruskultur, direktem Immunfluoreszenz und PCR zeigte bei Patienten mit akutem Asthma eindeutig, dass mit der PCR signifikant häufiger Atemwegsviren nachgewiesen werden konnten als mit den anderen Verfahren [8]. Auch bei Patienten mit COPD lassen sich mittels PCR deutlich häufiger Atemwegsviren nachweisen [9]. Auch wenn die Antigennachweisverfahren kostengünstiger sind, schließt ein negatives Ergebnis aufgrund der geringeren Sensitivität eine Infektion letztlich nicht aus. Aufgrund der längeren Untersuchungsdauer und höheren Anforderungen an Probenentnahme, Transport und Untersuchungsverfahren kommen Viruskulturverfahren bei Atemwegsinfektionen seltener zur Anwendung. Da serologisch letztlich nur ein 4-facher Titeranstieg der Virus-spezifischen Antikörper zwischen 2 im Abstand von 7-10 Tagen entnommenen Serumproben zu einer gesicherten Diagnose führt, kann diese wenn überhaupt meist erst retrospektiv erfolgen. Zu beachten ist auch, dass ein fehlender Titeranstieg die Infektion nicht ausschließt, da die erste Serumprobe bereits zu spät, d. h. nach Anstieg der Antikörperspiegel entnommen worden sein könnte. Deshalb stellt die PCR-Untersuchung bei den meisten viralen Atemwegsinfektionen inzwischen die Methode der Wahl da. 


\begin{tabular}{|c|c|c|}
\hline & Virusnachweis & Viren \\
\hline Akute Tracheobronchitis & $8-50 \%$ & RSV, Rhino-, Corona-, Adeno-, Coxsackie-, Echoviren \\
\hline Akute COPD-Exazerbation & $40-46 \%$ & $\begin{array}{l}\text { Rhino-, Influenza-, RS-, Adeno-, Parainfluenza-, } \\
\text { Corona-, Metapneumoviren }\end{array}$ \\
\hline Akute Asthma-Exazerbation & $50-85 \%$ & Rhino-, Corona-, RS-, Influenzaviren \\
\hline Ambulant erworbene Pneumonie & $20 \%$ & $\begin{array}{l}\text { Influenza-, RS-, Parainfluenza-, Adeno-, HS-, Meta- } \\
\text { pneumo-, Varicella-, Entero-, Echo-, Mimi-, Masern-, } \\
\text { SARS und andere Coronaviren }\end{array}$ \\
\hline Immunsuppression & & Influenza, Parainfluenza, Adeno-, CM-, Rhinoviren \\
\hline
\end{tabular}

Tab. 3 Übersicht über die häufigsten durch Atemwegsviren ausgelösten Erkrankungen

\section{Klinische Bedeutung von Atemwegsviren $\nabla$ Erkältungskrankheiten, grippale Infekte, akute} Tracheobronchitis

Die akute Tracheobronchitis ist eine der häufigsten Krankheiten des Menschen überhaupt, wobei Kleinkinder und Kinder im Vorschulalter am häufigsten betroffen sind. Durchschnittlich erkranken Schulkinder 2-6mal im Jahr und Erwachsene 2-3mal im Jahr [10]. Aktuelle Zahlen aus Großbritannien zeigen eine Prävalenz von 44/1000 Erkrankungen bei Erwachsenen (älter als 16 Jahre) pro Jahr, wobei $82 \%$ der Episoden im Herbst und Winter auftreten [11]. Die akute Bronchitis stellt den fünfthäufigsten Grund für einen Hausarztbesuch dar, wie eine Erhebung in Australien fand [12]. Als Hauptauslöser der Erkrankung werden Infektionen angesehen, allerdings können aber nur in weniger als 55\% aller Fälle pathogene Keime nachgewiesen werden [11]. Atemwegsviren scheinen die häufigsten Erreger zu sein, sie können aber nur in $8-23 \%$ aus dem Sputum von betroffenen Patienten isoliert werden. Ähnlich wie bei der chronisch obstruktiven Lungenerkrankung (COPD) muss jedoch davon ausgegangen werden, dass die Nachweisrate durch den Einsatz molekularbiologischer Verfahren wie der PCR erheblich gesteigert werden könnte [13]. In einer deutschen Studie bei Kindern unter 3 Jahren mit Infektion der unteren Atemwege konnten immerhin in ca. 50\% der Fälle mittels PCR das respiratorische Synzytialvirus (RSV), Influenza- oder Parainfluenzaviren nachgewiesen werden [14]. In derselben Patientengruppe fanden sich darüber hinaus zusätzlich Infektionen mit den erst kürzlich entdeckten Coronavirus NL63, das insbesondere mit der Krupp-Symptomatik assoziiert war [15]. Das Erregerspektrum umfasst weiterhin Rhino-, Adeno-, Coxsackie- und Echoviren ( $\bullet$ Tab.3).

Es konnten bislang keine spezifischen Risikofaktoren identifiziert werden und es ist weiterhin unklar, ob das inhalative Zigarettenrauchen das Erkrankungsrisiko erhöht. Es gibt jedoch epidemiologische Hinweise dafür, dass die Erkrankungshäufigkeit jeweils nach den Schulferien ansteigt, was darauf hindeutet, dass Menschenansammlungen die Verbreitung der Erkrankung fördern [10].

\section{Akute Exazerbation der COPD}

Epidemiologische Studien haben eine Korrelation der jährlichen Zunahme der Influenza-Aktivität und der Krankenhausaufnahmen wegen COPD-Exazerbationen gezeigt [16]. Dies macht Influenza, als Vertreter der Atemwegsviren, als Auslöser wahrscheinlich. Bislang ging man davon aus, dass ca. 50\% der Exazerbationen bakterieller und ca. 30\% der Exazerbationen viraler Genese seien [17]. Diese Angaben beruhten auf Daten, die in prospektiven Longitudinal-Studien in den 70er und 80er Jahren erhoben wurden [18-20]. Die damals verwendeten Verfahren für den Virusnachweis (Viruskultur und Serologie) hatten jedoch den oben beschriebenen Nachteil, dass sie wenig sensibel waren. Seit der Einführung der deutlich sensibleren PCR haben sich daher neue Aspekte ergeben. Aktuelle Arbeiten aus Großbritannien haben gezeigt, dass nahezu $40 \%$ aller ambulanten Exazerbationen mit Viren assoziiert sind [21]. Unsere eigene Arbeitsgruppe konnte unter Verwendung der PCR zeigen, dass die Prävalenz viraler Exazerbationen bei hospitalisierten Patienten deutlich unterschätzt wird und man davon ausgehen muss, dass mehr als die Hälfte aller Exazerbationen mit dem Nachweis von Atemwegsviren assoziiert ist [13]. Am häufigsten werden Picornaviren (Rhinovirus und Enterovirus) nachgewiesen (36\% aller Viren), gefolgt von Influenza A (25\%) und RSV (22\%). Picornaviren wurden auch in weiteren aktuellen Studien als häufigste virale Erreger identifiziert $[9,22]$.

Auch das kürzlich erstmals bei einem Kind mit unterer Atemwegsinfektion isolierte humane Metapneumovirus lässt sich bei der COPD-Exazerbation nachweisen. Die bislang vorliegenden Daten ergeben eine Prävalenz bei hospitalisierten Patienten mit akuter COPD-Exazerbation zwischen $0 \%$ und 12\% [23-25]. Da eine asymptomatische Besiedlung mit dem Virus unwahrscheinlich ist und in unseren Untersuchungen in allen Fällen eine relevante Viruslast nachgewiesen werden konnte [23], kommt dieses Virus jedoch als Auslöser einer COPD-Exazerbation durchaus infrage und sollte in zukünftige diagnostische und therapeutische Überlegungen mit einbezogen werden. Dies umso mehr, als starke saisonale und auch geografische Unterschiede in der Prävalenz wahrscheinlich sind.

\section{Atemwegsviren bei stabiler COPD}

Auch bei der stabilen COPD lassen sich mittels PCR Atemwegsviren im induzierten Sputum nachweisen [13,21], wobei ein Nachweis mittels Kultur oder Serologie bislang nicht gelang. Am häufigsten wird hier RSV nachgewiesen, wobei die Viruslast sehr niedrig ist [3]. Nichtsdestotrotz finden sich aber in RSV-positiven Patienten erhöhte systemische Entzündungsparameter, was das Vorliegen einer chronischen Infektion wahrscheinlich macht. Darüber hinaus zeigt sich bei diesen Patienten eine Tendenz zu häufigeren Exazerbationen [21]. Patienten mit häufigem Nachweis von RSV (in $>50 \%$ aller Proben auch während der stabilen Phase) zeigen eine beschleunigte Abnahme der Lungenfunktion zusammen mit einer verstärkten lokalen Entzündungsreaktion [26]. Seit längerem wird angenommen, dass Adenoviren zu latenten Infektionen bei Patienten mit COPD führen [27] und die chronische Entzündung verstärken [28]. Aktuelle epidemiologische Daten weisen jedoch darauf hin, dass dieses Phänomen relativ selten zu beobachten ist [29]. Insgesamt zeigen diese Daten aber, dass Atemwegsviren auch eine Rolle bei dem Verlauf der Erkrankung spielen. Systematische Daten zur Bedeutung von Atemwegsviren bei der stabilen COPD fehlen bislang. 
Akute Exazerbation des Asthma bronchiale

Die Mehrheit aller akuten Asthma-Exazerbationen wird durch Infekte der oberen Atemwege ausgelöst [30]. Dies wurde in epidemiologischen Studien sowohl bei Kindern (Nachweis bei bis zu 80\% der Exazerbationen) [31] als auch bei Erwachsenen (Nachweis bei ca. 50\%) [32] mittels virologischer Bestätigung überzeugend gezeigt. Mit Abstand am häufigsten werden Rhinoviren nachgewiesen, gefolgt von Coronaviren, Influenza und RSV. Hierbei ist auffällig, dass die Krankenhausaufnahmen wegen akuter Asthma-Exazerbationen mit dem generellen Nachweis von Atemwegsviren und auch mit dem Beginn der Schulhalbjahre korrelieren [33]. Experimentelle Infektionen bei Asthmatikern mit Rhinoviren konnten eine ursächliche Rolle der Viren bei der Exazerbation belegen [34]. Unterstützt wird dies dadurch, dass auch in Biopsien der unteren Atemwege Rhinoviren nachweisbar sind als Hinweis darauf, dass Rhinoviren nicht nur die oberen, sondern auch die unteren Atemwege infizieren können [35]. Kürzlich konnte gezeigt werden, dass es bei Asthmatikern zu verlängerten und schwereren Symptomen kommt [36] und die Virusreplikation stärker ausgeprägt ist [37]. Es wird vermutet, dass durch eine verminderte Produktion des antiviralen Faktors Interferon- $\beta$ bedingt ist [37].

\section{Die Bedeutung von Viren bei der ambulant erworbenen Pneumonie}

Eine ambulant erworbene Pneumonie (Community-Acquired Pneumonia, CAP) ist eine akute mikrobielle Infektion des Lungenparenchyms, die im ambulanten Bereich erworben wurde. In den neuesten epidemiologischen CAP-Studien konnten durch die neuen Untersuchungsmethoden verstärkt Viren als mögliche Erreger einer CAP bei bis zu 20\% der Fälle nachgewiesen werden $([38,39] / C A P N E T Z)$. Dabei wurde Influenza A mit Abstand als häufigster viraler Erreger nachgewiesen, gefolgt von Influenza $B$ und RSV $[38,40,41]$. Folgende andere Viren wurden vereinzelt gefunden: Parainfluenzavirus 1-4, Adenovirus, Herpes simplexVirus, Humanes Metapneumovirus, Varizellavirus, Enterovirus und Echovirus [24,38,40,42-46]. Auch sehr seltene Viren wie das Mimivirus konnten im respiratorischen Sekret bei Patienten mit ambulant erworbener Pneumonie nachgewiesen werden [47]. Als Verursacher der seltenen schwer verlaufenden viralen ambulant erworbenen Pneumonie wurden Influenza A-, Masern-, SARS-CoV und andere Coronaviren beschrieben [48-51]. In einigen Studien werden als Hinweise auf eine klinisch bedeutsame Infektion vermehrtes Auftreten von Leukopenie, Myalgien sowie trockener Husten beschrieben; zuverlässige klinische Parameter (Symptome, Laborparameter oder Röntgenbild) zum Nachweis einer viralen CAP existieren nicht [38-40,52].

Obwohl Atemwegsviren aufgrund der virologischen Befunde also eine wichtige Rolle bei der CAP spielen könnten, ist ihre Rolle bei der nosokomialen Pneumonie oder der Respirator-assoziierten Pneumonie bislang wenig erforscht. In einer eigenen Untersuchung wurde das Trachealsekret von 65 Intensivpatienten ohne pulmonale Infektion kurz nach der Intubation und im Verlauf auf atemwegspathogene Viren untersucht. Dabei wurden bei nur 3 Patienten Viren (Influenza A, RSV und humanes Rhinovirus (HRV)) nachgewiesen. Die Inzidenz nahm im Verlauf unter invasiver Beatmung nicht zu [53]. Interessanterweise haben beatmete Patienten mit Virusnachweis einen günstigeren Verlauf als solche, ohne Virusnachweis [54]. Ob es sich hierbei um einen kausalen Zusammenhang handelt, ist bislang ungeklärt. Falls sich diese Daten jedoch bestätigen sollten, so könnte die Diagnostik auf Atemwegsviren in diesem Kollektiv einen großen
Stellenwert erlangen, da dann eine Risikostratifizierung möglich wäre.

\section{Neue Atemwegsviren: das humane Bocavirus,} WU und KI Polyomavirus

Das humane Bocavirus (HBoV) ist ein hochkonserviertes Virus der Familie Parvoviridae. Es wurde 2005 erstmals im Rahmen eines molekularen Screeningprojekts mittels PCR mit einer Häufigkeit von 3,1\% in nasopharyngealen Aspiraten (NPA) schwedischer Kinder mit akuten oberen und tiefen Atemwegsinfektionen nachgewiesen [55]. Bis heute ist der definitive Nachweis einer klinisch relevanten, pathogenetischen Rolle bei der Verursachung tiefer Atemwegsinfektionen schwierig. Zahlreiche retround prospektive Untersuchungen zeigen eine deutliche Assoziation von $\mathrm{HBoV}$ zu obstruktiv verlaufenden, akuten tiefen Atemwegsinfektionen, Bronchiolitiden und Pneumonien. Junge Kleinkinder, aber auch erwachsene Patienten mit strukturellen Lungenerkrankungen oder Immundefekten scheinen betroffen zu sein [56-63]. Erste Erkenntnisse sprechen für einen virämischen Verlauf der akuten HBoV-Infektion [59]. HBoV wurde mittlerweile auch im Zusammenhang mit akuten Gastroenteritiden beschrieben [64-66] und scheint weltweit sowie saisonal gehäuft vorzukommen. In Anhängigkeit vom verwendeten PCRAssay und dem Ursprungsland der Untersuchung lag die Häufigkeit des HBoV-Nachweises in Atemwegssekreten in der Literatur zwischen 1,5\% [67] und 18,3\% [68]. Für Deutschland wurde kürzlich eine Häufigkeit von 12,0\% mit einer medianen Viruslast $4,9 \times 10^{3} \mathrm{Kopien} / \mathrm{ml}$ in NPA von Kindern mittels eines sensitiven Realtime-PCR-Assays sowie eine hohe Rate an viralen Co-Infektionen von ca. $40 \%$ gezeigt [69]. In der ersten Untersuchung zur Seroepidemiologie der HBoV-Infektion aus Japan hatten alle 204 untersuchten Kinder bis zum Alter von 6 Jahren Antikörper der Klasse IgG entwickelt [70], was die ubiquitäre Verbreitung unterstreicht.

Die jüngsten Mitglieder der Familie der neuen Atemwegsviren sind das WU (WUV, Washington University)- und KI (KIPyV, Karolinska Institut)-Polyomavirus [71-73], deren ätiologisches Potenzial zur Verursachung einer klinisch bedeutsamen Atemweginfektion jedoch bereits angezweifelt wird [74].

\section{Atemwegsviren bei Immunsuppression}

Atemwegsviren sind bei immunsupprimierten Patienten mit länger andauernden Infektionen, einer erhöhten Progressionsrate zu Infektionen der unteren Atemwege und einer erhöhten Mortalität assoziiert $[75,76]$. Es wurde gezeigt, dass mehr als 60\% der Patienten mit einer oberen Atemwegsinfektion eine Pneumonie entwickeln [76]. Bestimmte Atemwegsviren inklusive Influenza $A$ und $B$, Parainfluenza und Adenoviren sind auch mit einem erhöhten Abstoßungsrisiko bei solider Organtransplantation verbunden [77].

Letztendlich können alle bekannten Atemwegsviren bei Patienten mit Immunsuppression zu schweren Komplikationen führen.

Eine Infektion mit CMV ist ein wesentlicher Grund für Morbidität und Mortalität bei lungentransplantierten Patienten. Die Inzidenz von CMV wird mit 54 - 92 \% bei Patienten ohne CMV-Prophylaxe angegeben $[78,79]$. Der wichtigste Risikofaktor ist ein infizierter Spender bei seronegativem Empfänger [79]. Eine verlässliche Diagnostik ist daher von großer Bedeutung. Es stehen eine Reihe von Nachweisverfahren zur Verfügung, die Shell vial assays, den Nachweis des pp65 Antigens im Serum, PCR-Verfahren und Hybrid capture assays einschließen [80]. Vor allem für 
die Verlaufsbeurteilung hat sich der Einsatz quantitativer Realtime-PCR-Verfahren zur Bestimmung der Viruslast im Vollblut als sehr wichtig erwiesen [81].

Auch Adenoviren spielen eine wichtige Rolle bei transplantierten Patienten. Es wird vermutet, dass es zu einer Reaktivierung einer latenten Infektion unter der Immunsuppression kommt [82], dies ist bislang aber noch nicht definitiv gesichert [83]. Bei Patienten mit Stammzell-Transplantation werden Inzidenzen zwischen $5 \%$ und $47 \%$ angegeben [84-87]. Adenovirusinfektionen sind häufiger bei allogener als bei autologer Transplantation [83]. Die Datenlage für Organtransplantationen ist bislang noch nicht ausreichend, um die Inzidenz sicher angeben zu können. Für den Nachweis stehen auch hier mehrere Verfahren zur Verfügung (Viruskultur, Shell vial assay, Enzym Immunoassays (EIA)), wobei der quantitativen PCR mit Abstand die größte Bedeutung zukommt [88]. Meist wird das Vollblut untersucht, es können aber auch Urin, Stuhl, Sputum und Biopsien getestet werden [83].

Auch chronische Infektionen mit Rhinoviren wurden kürzlich bei Patienten mit Lungentransplantation mittels PCR nachgewiesen [89]. Schon seit längerem ist bekannt, dass Influenza [90] und RSV [91] ebenfalls zu gefährlichen Infektionen bei diesen Patienten führen können. Einen guten Überblick über diese und weitere relevante Viren wie Parainfluenzaviren, humanes Metapneumonvirus und Herpesviren gibt der aktuelle Übersichtsartikel von Lee und Barton [92].

In den letzten Jahren hat sich auch bei diesen Patienten der Nachweis von Atemwegsviren mittels PCR zunehmend durchgesetzt [93], so dass die anderen Verfahren deutlich in den Hintergrund rücken.

\section{Fazit}

$\nabla$

Atemwegsviren sind für die überwiegende Mehrzahl aller so genannten Erkältungskrankheiten und grippalen Infekte in der kalten Jahreszeit sowie der akuten respiratorischen Erkrankungen im Kindesalter verantwortlich. Bei akuten Exazerbationen vor allem des Asthma bronchiale, aber auch der chronisch obstruktiven Lungenerkrankung (COPD) sind sie in mehr als der Hälfte der Fälle als Auslöser anzusehen. Weiterhin spielen sie eine nicht zu vernachlässigende Rolle bei der ambulant erworbenen Pneumonie. Patienten mit Immunsuppression haben ein deutlich erhöhtes Risiko für virale Infektionen und einen schweren Verlauf mit deutlich erhöhter Mortalität. In den letzten Jahren hat sich die PCR als wichtigstes diagnostisches Instrument durchgesetzt und neue Entwicklungen zielen in Richtung vereinfachter Verfahren, um möglichst schnell ein Panel an relevanten Atemwegsviren detektieren zu können. Weiterhin wird die Identifizierung bislang noch unbekannter Atemwegsviren angestrebt. Leider ist es bis heute noch nicht gelungen, eine flächendeckende und kosten-effiziente Diagnostik anzubieten. Hier sind sowohl die Wissenschaft und Forschung als natürlich auch die Politik gefordert, um dies zu ermöglichen, da allein die durch Atemwegsviren verursachten volkswirtschaftlichen Kosten hoch sind und somit diagnostische und daraus abzuleitende therapeutische Konzepte zumindest mittelfristig kosteneffizient werden können. Auch wird erst durch eine gute Diagnostik der große Stellenwert der Infektionen durch Atemwegsviren deutlicher erkennbar werden, was den Druck auf die Pharmaindustrie zur Entwicklung neuer therapeutischer Ansätze fördern wird [94].

\section{Literatur}

1 Modrow S, Falke D, Truyen U. Labormethoden zum Nachweis von Virusinfektionen. Molekulare Virologie. 2.ed. Heidelberg-Berlin: Spektrum Akademischer Verlag GmbH, 2003: 114-129

2 Marshall DJ, Reisdorf E, Harms G et al. Evaluation of a Multiplexed PCR Assay for Detection of Respiratory Viral Pathogens in a Public Health Laboratory Setting. J Clin Microbiol 2007; 45: 3875- 3882

3 Borg I, Rohde G, Loeseke S et al. Evaluation of a quantitative real-time PCR for the detection of RSV in pulmonary diseases. Eur Respir J 2003; 21: $944-951$

4 Ieven $M$. Currently used nucleic acid amplification tests for the detection of viruses and atypicals in acute respiratory infections. J Clin Virol 2007; 40: 259-276

5 Stang A, Korn K, Wildner 0 et al. Characterization of Virus Isolates by Particle-Associated Nucleic Acid PCR. J Clin Microbiol 2005; 43: 716 720

6 Ambrose HE, Clewley JP. Virus discovery by sequence-independent genome amplification. Rev Med Virol 2006; 16: 365 - 383

7 Janeway CA Jr, Travers $P$, Walport $M$ et al. D. Structure of the antibody molecule and the immunoglobulin genes. In: Janeway Jr. CA (ed). Immunobiology: the immune system in health and disease. 4.ed. London/New York: Elsevier Science Ltd/Garland Publishing, 1999: 79113

8 Xiang X, Qiu D, Chan KP et al. Comparison of three methods for respiratory virus detection between induced sputum and nasopharyngeal aspirate specimens in acute asthma. J Virol Methods 2002; 101: 127 133

9 Beckham JD, Cadena A, Lin J et al. Respiratory viral infections in patients with chronic, obstructive pulmonary disease. J Infect 2005; 50: $322-330$

10 Monto AS, Ullman BM. Acute respiratory illness in an American community. The Tecumseh study. JAMA 1974; 227: 164-169

11 Macfarlane J, Holmes W, Gard $P$ et al. Prospective study of the incidence, aetiology and outcome of adult lower respiratory tract illness in the community. Thorax 2001; 56: 109-114

12 Meza RA, Bridges-Webb C, Sayer GPet a l. The management of acute bronchitis in general practice: results from the Australian Morbidity and Treatment Survey, 1990-1991. Aust Fam Physician 1994; 23: $1550-1553$

13 Rohde G, Wiethege A, Borg I et al. Respiratory viruses in exacerbations of chronic obstructive pulmonary disease requiring hospitalization a case-control study. Thorax 2003; 58: $37-42$

14 Forster J, Ihorst G, Rieger $\mathrm{CH}$ et al. Prospective population-based study of viral lower respiratory tract infections in children under 3 years of age (the PRI.DE study). Eur J Pediatr 2004; 163: 709-716

15 Hoek $L$ van der, Sure K, Ihorst $G$ et al. Croup is associated with the novel coronavirus NL63. PLoS Med 2005 Aug ; 2 (8): e240

16 Yap FH, Ho PL, Lam KF et al. Excess hospital admissions for pneumonia, chronic obstructive pulmonary disease, and heart failure during influenza seasons in Hong Kong. J Med Virol 2004; 73: 617-623

17 Sethi S. Infectious etiology of acute exacerbations of chronic bronchitis. Chest 2000; 117: 380S-385S

18 Smith CB, Golden CA, Kanner RE et al. Association of viral and Mycoplasma pneumoniae infections with acute respiratory illness in patients with chronic obstructive pulmonary diseases. Am Rev Respir Dis 1980; $121: 225-232$

19 Gump DW, Phillips CA, Forsyth BR et al. Role of infection in chronic bronchitis. Am Rev Respir Dis 1976; 113: 465 - 474

20 Buscho RO, Saxtan D, Shultz PS et al. Infections with viruses and Mycoplasma pneumoniae during exacerbations of chronic bronchitis. J Infect Dis 1978; 137: 377- 383

21 Seemungal T, Harper-Owen R, Bhowmik A et al. Respiratory Viruses, Symptoms, and Inflammatory Markers in Acute Exacerbations and Stable Chronic Obstructive Pulmonary Disease. Am J Respir Crit Care Med 2001; 164: 1618-1623

22 Hutchinson AF, Ghimire AK, Thompson MA et al. A community-based, time-matched, case-control study of respiratory viruses and exacerbations of COPD. Respir Med 2007; 101: 2472-2481

23 Rohde G, Borg I, Arinir U et al. Relevance of human metapneumovirus in exacerbations of COPD. Respir Res 2005; 6 : 150 doi : 0.1186/1465 $9921-6-150$

24 Hamelin ME, Cote S, Laforge J et al. Human metapneumovirus infection in adults with community-acquired pneumonia and exacerbation of chronic obstructive pulmonary disease. Clin Infect Dis 2005; 41: $498-502$ 
25 Martinello RA, Esper F, Weibel C et al. Human metapneumovirus and exacerbations of chronic obstructive pulmonary disease. J Infect 2006; 53: $248-254$

26 Wilkinson TM, Donaldson GC, Johnston SL et al. Respiratory Syncytial Virus, Airway Inflammation and $\mathrm{FEV}_{1}$ Decline in Patients with COPD. Am J Respir Crit Care Med 2006; 173: 871 - 876

27 Matsuse T, Hayashi S, Kuwano Ket al. Latent adenoviral infection in the pathogenesis of chronic airways obstruction. Am Rev Respir Dis 1992; 146: $177-184$

28 Retamales I, Elliott WM, Meshi B et al. Amplification of inflammation in emphysema and its association with latent adenoviral infection. Am J Respir Crit Care Med 2001; 164: 469-473

29 McManus TE, Marley AM, Baxter N et al. Acute and latent adenovirus in COPD. Respir Med 2007; 101: 2084 - 2090

30 Papadopoulos NG, Xepapadaki P, Mallia P et al. Mechanisms of virusinduced asthma exacerbations: state-of-the-art. A GA(2)LEN and InterAirways document. Allergy 200726; 62: 457-470

31 Johnston SL, Pattemore PK, Sanderson G et al. Community study of role of viral infections in exacerbations of asthma in 9-11 year old children. BMJ 1995; 310: 1225-1229

32 Nicholson KG, Kent J, Ireland DC. Respiratory viruses and exacerbations of asthma in adults. BMJ 1993; 307: 982 - 986

33 Johnston SL, Pattemore PK, Sanderson G et al. The relationship between upper respiratory infections and hospital admissions for asthma: A time-trend analysis. Am J Respir Crit Care Med 1996; 154: 654-660

34 Grunberg K, Timmers MC, de Klerk EP et al. Experimental rhinovirus 16 infection causes variable airway obstruction in subjects with atopic asthma. Am J Respir Crit Care Med 1999; 160: 1375 - 1380

35 Papadopoulos NG, Bates PJ, Bardin PG et al. Rhinoviruses infect the lower airways. J Infect Dis 2000; 181: $1875-1884$

36 Corne JM, Marshall C, Smith S et al. Frequency, severity, and duration of rhinovirus infections in asthmatic and non-asthmatic individuals: a longitudinal cohort study. Lancet 2002; 359: 831 - 834

37 Wark PA, Johnston SL, Bucchieri F et al. Asthmatic bronchial epithelial cells have a deficient innate immune response to infection with rhinovirus. J Exp Med 2005; 201: 937-947

38 de Roux A, Marcos MA, Garcia E et al. Viral community-acquired pneumonia in nonimmunocompromised adults. Chest 2004; 125: 1343 1351

39 Angeles MM, Camps M, Pumarola T et al. The role of viruses in the aetiology of community-acquired pneumonia in adults. Antivir Ther 2006; 11: $351-359$

40 Dowell SF, Anderson LJ, Gary HE Jr et al. Respiratory syncytial virus is an important cause of community-acquired lower respiratory infection among hospitalized adults. J Infect Dis 1996; 174: 456- 462

41 Ruiz M, Ewig S, Marcos MA et al. Etiology of community-acquired pneumonia in hospitalized patients: Impact of age, comorbidity and severity. Am J Respir Crit Care Med 1999; 160: 397-405

42 Krech T, Wegmann T, Martin H et al. Etiology of atypical pneumonias. A serological study on 1494 patients. Schweiz Med Wochenschr 1986; 116: $2-7$

43 Farr BM, Kaiser DL, Harrison BD et al. Prediction of microbial aetiology at admission to hospital for pneumonia from the presenting clinical features. British Thoracic Society Pneumonia Research Subcommittee. Thorax 1989; 44: 1031 - 1035

44 Dahmash NS, Chowdhury MN. Re-evaluation of pneumonia requiring admission to an intensive care unit: a prospective study. Thorax 1994; 49: $71-76$

45 Bohte R, Furth R van, Broek PJ van den. Aetiology of community-acquired pneumonia: a prospective study among adults requiring admission to hospital. Thorax 1995; 50: 543-547

46 Socan M, Marinic-Fiser N, Kraigher A et al. Microbial aetiology of community-acquired pneumonia in hospitalised patients. Eur J Clin Microbiol Infect Dis 1999; 18: 777 - 782

47 La SB, Marrie TJ, Auffray JP et al. Mimivirus in pneumonia patients. Emerg Infect Dis 2005; 11: 449-542

48 Woo PCY, Lau SKP, Tsoi Hw et al. Clinical and Molecular Epidemiological Features of Coronavirus HKU1-Associated Community-Acquired Pneumonia. The Journal of Infectious Diseases 20051; 192: 1898 1907

49 Cebular S, Lee S, Tolaney P et al. Community-acquired pneumonia in immunocompromised patients. Opportunistic infections to consider in differential diagnosis. Postgrad Med 2003; 113: 65-70, 73
50 Duffau P, Moiton MP, Lafon ME et al. A case of severe community acquired pneumonia and non-respiratory illness induced by Influenza A. Med Mal Infect 2006; 36: $473-475$

51 Lee $\mathrm{N}$, Rainer TH, Ip $\mathrm{M}$ et al. Role of laboratory variables in differentiating SARS-coronavirus from other causes of community-acquired pneumonia within the first $72 \mathrm{~h}$ of hospitalization. Eur J Clin Microbiol Infect Dis 2006; 25: 765-772

52 Jennings LC, Anderson TP, Beynon KA et al. Incidence and Characteristics of Viral Community-Acquired Pneumonia in Adults. Thorax 2008; 63: $42-48$

53 Schlosser B, Rohde G, Borg I et al. Viral and bacterial colonization in intubated patients in the ICU. Proc Am Thorac Soc 2005; 2: A822

54 Daubin C, Parienti JJ, Vincent $S$ et al. Epidemiology and clinical outcome of virus-positive respiratory samples in ventilated patients: a prospective cohort study. Crit Care 20065; 10: R142

55 Allander T, Tammi MT, Eriksson $M$ et al. Cloning of a human parvovirus by molecular screening of respiratory tract samples. Proc Natl Acad Sci 2005; 102: 12891 - 12896

56 Khetsuriani N, Kazerouni NN, Erdman DD et al. Prevalence of viral respiratory tract infections in children with asthma. Journal of Allergy and Clinical Immunology 2007; 119: 314-321

57 Kleines M, Scheithauer S, Rackowitz A et al. High Prevalence of Human Bocavirus Detected in Young Children with Severe Acute Lower Respiratory Tract Disease by Use of a Standard PCR Protocol and a Novel Real-Time PCR Protocol. J Clin Microbiol 2007; 45: 1032- 104

58 Kupfer B, Vehreschild J, Cornely $O$ et al. Severe pneumonia and human bocavirus in adult. Emerg Infect Dis 2006; 12: 1614- 1616

59 Allander T, Jartti T, Gupta S et al. Human bocavirus and acute wheezing in children. Clin Infect Dis 2007; 44: $904-910$

60 Chung JY, Han TH, Kim SW et al. Detection of viruses identified recently in children with acute wheezing. J Med Virol 2007; 79: 1238-1243

61 Fry AM, Lu X, Chittaganpitch $M$ et al. Human bocavirus: a novel parvovirus epidemiologically associated with pneumonia requiring hospitalization in Thailand. J Infect Dis 2007; 195: 1038 - 1045

62 Gendrel D, Guedj R, Pons-Catalano C et al. Human bocavirus in children with acute asthma. Clin Infect Dis 2007; 45: 404-405

$63 \mathrm{Kim}$ YJ, Boeckh M, Englund JA. Community respiratory virus infections in immunocompromised patients: hematopoietic stem cell and solid organ transplant recipients, and individuals with human immunodeficiency virus infection. Semin Respir Crit Care Med 2007; 28: 222 242

64 Lee JI, Chung JY, Han TH et al. Detection of human bocavirus in children hospitalized because of acute gastroenteritis. J Infect Dis 2007; 196: 994-997

65 Lau SK, Yip CC, Que TL et al. Clinical and molecular epidemiology of human bocavirus in respiratory and fecal samples from children in Hong Kong. J Infect Dis 2007; 196: 986 - 993

66 Vicente D, Cilla G, Montes $M$ et al. Human bocavirus, a respiratory and enteric virus. Emerg Infect Dis 2007; 13: 636-637

67 Bastien N, Brandt K, Dust K et al. Human Bocavirus infection, Canada. Emerg Infect Dis 2006; 12: $848-850$

68 Kaplan NM, Dove W, Bu-Zeid AF et al. Human bocavirus infection among children, Jordan. Emerg Infect Dis 2006; 12: 1418-1420

69 Neske F, Blessing K, Tollmann F et al. Real-time PCR for diagnosis of human bocavirus infections and phylogenetic analysis. J Clin Microbiol 2007; 45: 2116 - 2122

70 Endo R, Ishiguro N, Kikuta $\mathrm{H}$ et al. Seroepidemiology of human bocavirus in Hokkaido prefecture, Japan. J Clin Microbiol 2007; 45: 3218 3223

71 Allander T, Andreasson K, Gupta S et al. Identification of a third human polyomavirus. J Virol 2007; 81: 4130-4136

72 Bialasiewicz S, Whiley DM, Lambert SB et al. A newly reported human polyomavirus, KI virus, is present in the respiratory tract of Australian children. J Clin Virol 2007; 40: 15 - 18

73 Gaynor AM, Nissen MD, Whiley DM et al. Identification of a novel polyomavirus from patients with acute respiratory tract infections. PLoS Pathog 2007; 3: e64

74 Norja P, Ubillos I, Templeton K et al. No evidence for an association between infections with WU and KI polyomaviruses and respiratory disease. J Clin Virol 2007; 40: 307-311

75 Englund JA. Diagnosis and epidemiology of community-acquired respiratory virus infections in the immunocompromised host. Biol Blood Marrow Transplant 2001; 7: 2S-4S 
76 Couch RB, Englund JA, Whimbey E. Respiratory viral infections in immunocompetent and immunocompromised persons. Am J Med 1997; 102: $2-9$

77 Barton TD, Blumberg EA. Viral pneumonias other than cytomegalovirus in transplant recipients. Clin Chest Med 2005; 26: 707-720

78 Duncan AJ, Dummer JS, Paradis IL et al. Cytomegalovirus infection and survival in lung transplant recipients. J Heart Lung Transplant 1991; 10: $638-644$

79 Ettinger NA, Bailey TC, Trulock EP et al. Cytomegalovirus infection and pneumonitis. Impact after isolated lung transplantation. Washington University Lung Transplant Group. Am Rev Respir Dis 1993; 147: $1017-123$

80 Zamora MR, Davis RD, Leonard C. Management of cytomegalovirus infection in lung transplant recipients: evidence-based recommendations. Transplantation 2005; 80: 157- 163

81 Humar A, Paya C, Pescovitz MD et al. Clinical utility of cytomegalovirus viral load testing for predicting CMV disease in D+/R- solid organ transplant recipients. Am J Transplant 2004; 4: 644-649

82 Venard V, Carret A, Corsaro $D$ et al. Genotyping of adenoviruses isolated in an outbreak in a bone marrow transplant unit shows that diverse strains are involved. J Hosp Infect 2000; 44: $71-74$

83 Ison MG. Adenovirus infections in transplant recipients. Clin Infect Dis 20061; 43: 331 - 339

84 Runde $V$, Ross $S$, Trenschel $R$ et al. Adenoviral infection after allogeneic stem cell transplantation (SCT): report on 130 patients from a single SCT unit involved in a prospective multi center surveillance study. Bone Marrow Transplant 2001; 28: 51 - 57

85 Chakrabarti S, Mautner V, Osman H et al. Adenovirus infections following allogeneic stem cell transplantation: incidence and outcome in re- lation to graft manipulation, immunosuppression, and immune recovery. Blood 2002; 100: 1619-1627

86 Baldwin A, Kingman H, Darville $M$ et al. Outcome and clinical course of 100 patients with adenovirus infection following bone marrow transplantation. Bone Marrow Transplant 2000; 26: 1333-1338

87 Shields AF, Hackman RC, Fife KH et al. Adenovirus infections in patients undergoing bone-marrow transplantation. N Engl J Med 1985; 312: $529-533$

88 Claas EC, Schilham MW, de Brouwer CS et al. Internally controlled realtime PCR monitoring of adenovirus DNA load in serum or plasma of transplant recipients. J Clin Microbiol 2005; 43: 1738-1744

89 Kaiser L, Aubert JD, Pache JC et al. Chronic rhinoviral infection in lung transplant recipients. Am J Respir Crit Care Med 2006; 174: 1392 1399

90 Nichols WG, Guthrie KA, Corey L et al. Influenza infections after hematopoietic stem cell transplantation: risk factors, mortality, and the effect of antiviral therapy. Clin Infect Dis 2004; 39: 1300-1306

91 Small TN, Casson A, Malak SF et al. Respiratory syncytial virus infection following hematopoietic stem cell transplantation. Bone Marrow Transplant 2002; 29: 321 - 327

92 Lee I, Barton TD. Viral respiratory tract infections in transplant patients: epidemiology, recognition and management. Drugs 2007; 67: $1411-1427$

93 Kraaij MG van, Elden LJ van, Loon AM van et al. Frequent detection of respiratory viruses in adult recipients of stem cell transplants with the use of real-time polymerase chain reaction, compared with viral culture. Clin Infect Dis 2005; 40: 662-669

94 Rohde G. Therapeutic targets in respiratory viral infections. Curr Med Chem 2007; 14: $2776-2782$ 